\title{
The Challenge of Post-Modernism
}

\author{
Mariette Hellemans \\ University of Leuven
}

Post-modern thought is truly putting educational theory to the test. Calling into question the autonomy of the subject is for many the equivalent of a pedagogical absurdity. Where, they ask themselves, is the need for education if the subject, down to the level of his or her most intimate thoughts, is in fact the product of history, language, and society? How can we speak of pedagogical responsibility if the possibility of a strictly personal conferment of meaning and signification is disputed?

The way we conceive of education, as is apparent from the questions above, is exemplary of a modern self-consciousness which identifies subjectivity with self-satisfaction and autonomy. From the perspective of this subjectivity, something which cannot be reassimilated by the subject can only be understood as an attack on this subjectivity. A freedom which justifies itself is not responsible for something taken away from the initiative of this freedom.

Although it is conceded that what could be called the autonomy of the subject has become increasingly vague and that the stated freedom and independence have gradually become buried under concepts which focus on our being determined, it would appear that educational theorists are not yet prepared to dispense with the concept of autonomy. Notwithstanding the fact that pedagogical practice has lost its innocence and self-evident naturea state of affairs linked with the developments of modernity - the general tendency in the field of educational theory is to carry on implementing the modern vision of "educational theory" (Mollenhauer, 1986, p. 8). One is prepared to temper pedagogical ambitions, to leave room for legitimate doubt as to the effects of pedagogical activities, to recognize their embedment in surrounding and encompassing systems, and consequently one is also prepared to recognize the limits of pedagogical responsibility. Under no circumstances, however, is one prepared to relinquish the responsibility for the future of our children ( $p$. 10); and this implies the retention of the concept of autonomy. 
The question is, however, whether the responsibility for the future of the child is inherently linked to the presuppositions of a modern theory of education. Why should it be pedagogically absurd to call the autonomy of the subject into question? Why should it become impossible to speak of pedagogical responsibility if education is separated from the intentions of the educator?

\section{The Vision of the Moderns}

Post-modernism puts an end to the self-consciousness of the modern person. The basic outlines of this self-consciousness were sketched during a relatively short period of history. Hazard (1961), in his brilliant work The Crisis of European Consciousness, situates the origins of the modern period between 1680 and 1715. In this period, according to Hazard, a revolution takes place: Religion is ousted by science, tradition by progress, and "ancient" man is ousted by "modern" man. "A stranger makes his appearance, Reason" (p. 109); a stranger rings in the end of a world which in fact seemed to be based on him.

For ancient man, Reason is the mediator of a religious-politicalsocial order (Hazard, 1961, p. 300). For the Greek, the structure of individual and communal existence can only transcend human arbitrariness when personal life as well as the polis represent the totality of the cosmos. Plato has let the state come into being on the basis of a common need, a common indigence. This does not, however, give rise solely to utilitarian agreements, as in "the social contract" (le contrat social). The state plays an educative role. The state is an instrument in the ordering of existence in accordance with the ordering of totality (Fink, 1970, pp. 13, 77). By way of the polis, the life of citizens is founded on the truth of being.

In the beginning of the 18 th century Reason reveals itself as the ordering principle. The question is no longer how the "order of things" can be known and realized, but how the order of things constitutes itself starting from the subject: the Cartesian proclamation of the metaphysical sovereignty of the thinking subject. Openness of being, which constitutes man's being and is one of the essential themes of the thinking of antiquity, is supplanted by the priority of the subject (Fink, 1970, p. 19). Reason is made independent and is deprived of its link with totality (Habermas, 1983a, p. 411).

Life as a whole is interpreted according to the model of a creative (production) process in which the artist's genius simultaneously brings a work into being and unfolds the totality of his own possibilities. Culture signifies both the objectivations in 
which subjectivity expresses itself and the formation of subjectivity itself. This process is an "educational process" (Bildungsprozess), and "the ultimate goal (telos) of this educational process is the enhancement of the life of the individual" (Habermas, 1983b, p. 247).

The risk inherent in such a Kantian and neo-Kantian concept of culture is that objective culture (which is the expression of subjectivity) should come to set itself against the individual subjects, and that the individuals should then be compelled to subordinate themselves. Thus progress - the development of culture-becomes an imminent threat to individuality (Habermas, 1983 b, pp. 246-249), a subjectivity which can no longer successfully reassimilate its own creation. In the Dialectic of the Enlightenment, Horkheimer and Adorno (1972) established that this threat had already become reality. Many others besides them have tried to answer the question as to why this development was inevitable and why alienation was inherent in the power position of Enlightenment man.

This question was, of course, still situated in the Enlightenment framework of reference. Others have called the presupposition of the question itself into question. They dispute the idea that the subject is the order-constituting agent. The subject is dethroned and the processes without subject enter onto the stage.

Habermas (1983b) was reluctant to draw this conclusion. The challenge implicit in the development of modernity forces him rather to a resumption (and revaluation) of the fundamental concepts of the philosophy of consciousness and of "the expressivistic educational ideal" (p. 251). In his opinion, the structuralists have not succeeded in transcending the presuppositions of the philosophy of consciousness (from which they had wanted to distance themselves). They have not dissolved the tension between objective culture and subjectivity, merely reversed the relationship. "In such a way the Other of Reason remains the mirror image of those who hold power" (Habermas, 1985, p. 360 ). Modern philosophical thought has tried to use the subject to restore the lost order of things. Structuralists attributed this role to transcendental-historical powers (a role which the "Philosophy of Life" [Lebensphilosophie] had already given to Life). The tension subjectivity-objectivity is insoluble and the favoring of one of the two is unavoidable as long as one remains "bound up with the intention of the Philosophy of origin (p. 346). Either subjectivity is the source of objectivity, or objectivity is the source of subjectivity. Habermas prefers to discuss the problems associated with this thinking in terms of subject-object. Thus Habermas appears to be the guide par excellence for an educa- 
tional theory which has to contend with the threat of supra-individual structures endangering the expressive ideal of self-responsible self-determination.

\section{Onlooker's Perspective Versus Participant's Perspective}

"We could have learned from Freud or Nietzsche that Reason without its Other does not exist and that, functionally speaking, it becomes necessary because of the Other" (Habermas, 1985, p. 355). This citation, which Habermas takes from a publication of Böhme and Bohme-a publication which, by the way, he does not find particularly praiseworthy-summarizes extremely well what Habermas considers to be the Achilles' heel of the Enlightenment. The ideal and at the same time the illusion of the modern subject is that it wants to be its own ground, dependent on no one and nothing except itself, and bound only by the "unconstrained constraint of better insight" (p. 356). In this supposed sovereignty, the subject becomes the plaything of nonreassimilable forces operating on the subject itself (p. 357).

According to Habermas, the manner in which Reason (Vernunft) is conceived invokes the other as a spontaneous, vital, unthinkable power which establishes being. In his opinion, structuralists cannot avoid this dialectic by placing the origin of subjectivity in the other. They undertake to make a critique of modern self-consciousness, of Reason, from the perspective of that other which is shut out by Reason. This is a remarkable endeavor, says Habermas, hereby referring to Heidegger and Foucault, both of whom, in his view, lay claim to being beyond the horizon of Reason without, however, being unreasonable (unvernünftig). Here subjectivity appears in the place traditionally occupied by the object. Reason displaces itself. The other remains that which is other than subjectivity. What structuralism offers is merely "a last, self-surpassing act of selfreflection" (Habermas, 1985, p. 359). The assumption is still that between the constituting and the constituted there exists an "ontological difference" (ontologische Differenz). This implies that the productive power is disassociated from the consequences of a praxis is has produced (or, in Derrida's terminology, between the language and the things talked about, p. 371).

The impasse arrived at by modern philosophy and the post-modern alternatives when they try to think about the relationship between subjectivity and the other is, according to Habermas, associated with the onlooker's perspective typical of these philosophies. The questions are posed from the point of view of a third party, looking on and asking himself or herself what is the 
origin of what. This question, in its apparent obviousness, is linked with the favoring of the paradigm of self-consciousness, the favoring of the objectifying predisposition with respect to reality (Habermas, 1985, p. 346); it is linked with the monopoly of a self-understanding in which being human goes together with the establishment of truth and the realization of goals (p. 362). At this stage, we will not follow Habermas any further in his critique of the paradigm of the knowing subject, because of greater importance with regard to our original problem is the alternative Habermas attempts to develop-an alternative to the onlooker's perspective.

Habermas maintains that the insoluble tension between subjectivity and objectivity (or, in the pedagogical terms for the problem, between autonomy and heteronomy) disappears from the perspective of partners in interaction who coordinate their actions in a shared understanding of the world. The model here is not the objectifying, but rather the performing predisposition. Habermas does not think from the perspective of the onlooker, but from the perspective of the participant. Habermas indicates, among other things, the meaningfulness of such a perspective by referring to the achievements of a present-day ethology in which there is agreement that it is not the propositional, but rather the communicative use of language that characterizes us as human beings.

Modern subjectivity is a reflexive subjectivity-a relatedness to itself as knowing and acting subject. The $I$ is a double I: It is a transcendental and an empirical I. The autonomous I, the I of self-reflection, is the onlooker with respect to the I intertwined with reality. From the perspective of the participant in the interaction, this ontological distinction disappears. Ego can, indeed, relate to itself from the perspective of Alter. The first person can from the perspective of the second person duplicate its actions - the first person reconstructs from the perspective of the other the knowledge taken into account in the interaction. There is no question, however, of a self-consciousness existing beyond the interaction (Habermas, 1985, p. 347). The reconstruction is not the radical self-reflection which reveals what is hidden behind the empirical, but rather the recovery of actually practiced knowledge (p. 348). From the perspective of the participant in the interaction, this knowledge of the rules sedimented in action allows itself to be thematized only insofar as it is inherent in the action.

Each deed or act of speech mobilizes a fragment out of the store of self-evident cultural goods which are both context and source of communication processes (Verständigungsprozesse). This 
store is the life world. The life world, which is omnipresent, cannot be exhaustively thematized because it is only reproduced through the speaking and acting of individuals. The productivity of the life world cannot be disassociated from the praxis of the inner world. A dialectic relationship exists between, on the one hand, the structures of the life world which make interaction possible and, on the other hand, learning processes which involve changing these structures.

Does this bridge the gap between the transcendental and the empirical? In Habermas' (1985) terms: Are the structures of the life world not the equivalent of "pure Reason" (p. 374). According to Habermas, rationality is and has always been incarnated rationality, incarnated in communicative action and in the structures of the life world. Rationality, from the individual's point of view, is being able to participate responsibly in interaction-subjectivity is not the source of meaning, but rather the user of meaning (p. 366). This rationality retains (as with the moderns) its consensus-forming power. To the degree that it involves the intersubjective claims to validity, interaction intertwines the social praxis with the context of the life world. The validity claimed in the interaction, situated in a particular timespace social context, does not indeed coincide with the general validity to which the factual consensus is oriented, but this general validity is the presupposition of the functioning of a claim which is made here and now (p. 375). This is the distinction which Apel (1971, pp. 7-45) made famous between the factual and the ideal communication community. The validity of a concrete interaction which coincides with success (or failure), and thus with an implicit yes (no) position with respect to factual claims of validity, refers to a line of argument regarding a hypothetical validity. This implicit level of argumentation is reflected in the discourse. At this reflexive level the speaker turns back to himself from the viewpoint of the one to whom he is oriented.

To illustrate this line of thought, Habermas (1985) refers to the Old Testament idea of the covenant that Jahweh concludes with Israel (p. 377). An individual breaking of this covenant is not possible. To break the covenant means not only to take away one's own foundation of being, but also that of the others. Betrayal of the others is always also betrayal of oneself. The other is fundamentally the ally. The $I$ is the ally of the other. On the other hand, the covenant is only what it is and it can only continue to exist in the concrete alliance. This alliance, according to Habermas, is certainly not established through the initiative of individuals. His critique of Hannah Arendt makes this 
clear. He borrows the concept of communicative action from Arendt, but his critique points out that she cannot really trust communicative action as long as she wants to seal it with a "social contract" (Masschelein, 1990, p. 20ff.).

Habermas wants to avoid the question of origin. He tries to circumvent it by thinking from the perspective of man as a partner in intersubjective communication. From this point of view, subjectivity is intersubjective. Even in a reflexive moment, the subject of interaction cannot take the other back into itself because the I that undertakes this effort is always referred back to a point of departure which is unavoidably situated in communication. Taking part in a demonstration against atomic weapons is just as much a manifestation of the $I$ as is not taking part in a demonstration. This taking part or not taking part derives its meaning from the generally accepted meaning of a demonstration. The $I$ is not the initiator of this meaning. It is the user of this meaning. This meaning, as Habermas argues in his discussion with structuralist philosophy of language, is not the product of an anonymous power, but the logos of communication.

Spontaneously the question arises: What is the foundation of this logos? The philosophy of the Enlightenment situates this foundation in the subject. The thought of antiquity made this logos inherent in reality. Habermas (1981) makes of rationality a communicative rationality and situates the logos in communication. All these cases refer to a speculative process which attempts to think of totality from the point of view of a favored experience. It is pointless to set these objects next to one another and to imagine a sort of synthesis in the sense of: Our meanings are intersubjective, but there is difference between the meaning which is intersubjective and what I mean by it.

Autonomy is a concept that imparted a logic to a reality. Thus it seemed obvious to turn this autonomous subjectivity into logos of reality. The reality which has to look to the subjective logos in order to find its logic seems ever more illogical, however, from the point of view of this order-creating agent. We may continue to defend ourselves determinedly against the unlimited socialpolitical power of a production system, but, on the other hand, we plead for a reconsideration of man's relationship with his natural environment. Irrationality forces us to reconsider rationality. And this is what Habermas (1985) does. Autonomy in the sense of "purposive self-assertion" (zweckrationale Selbstbehauptung) is for him an autonomous moment in intersubjective interaction, both a "separation" (Abspaltung) and a "usurpation"; it is one moment in a total process which has put itself in 
the place of totality though lacking the power to assimilate this totality (p. 367).

The ultimate question is whether the participant's perspective is a valid alternative to the onlooker's perspective. Is the experience of always being intertwined with expectations of which we are not the source a valid alternative to the experience of being the source of intelligibility?

\section{The Originality of the Ethical Relation}

Habermas is not alone in his efforts to develop another type of rationality. Levinas, with an entirely different background from that of Habermas, has also made an attempt at revalorization of an experience which through a dominant type of rationality was shut out of the philosophical discourse: namely, religious experience.

For Levinas (1951) our philosophical tradition is ontological. Philosophy is ontology. Philosophy was born out of the question: Why is there something rather than nothing? Up to and including Heidegger (who nevertheless intended the destruction of traditional ontology) philosophy remains, for Levinas in any case, dominated by the question as to the origin of beings. What lets beings be?

Levinas (1987) asks himself: Is this the only possible and valid philosophical question? Is the decision of the first Greek philosophy, that the good must be interpreted on the basis of the truth of being, irrevocable? Is it so against nature to ask the question "Is being justifiable" (p. 140)? The question as to the justification of existence, as to the meaning of existence, is already answered by the manner in which it was posed in the first philosophy. Why is there something rather than nothing? This already implied: being is-in being, there is no nonbeing. Being and meaning coincide.

The question which Levinas continually asks throughout his whole work is: Is a different relationship between subject and reality imaginable other than the ontological? According to Levinas (1987), in our history there is indeed another relationship that has been thematized, namely through religion (i.e., Judaism). The transcendental is not here the foundation of being, but "the invisible which makes demands of me" (l'invisible qui me demande), a question which puts me into question, a question of which I know neither the source nor the foundation, a question which comes to me in my relationship to the other human being, a question "by way of responsibility" (en 
guise de responsibility) a responsibility without ground and without guilt (p. 139).

Positing that I am responsible for the other means that my being is justifiable (Levinas, 1987, p. 69). I am not justified through my being. The question of justification is an ethical and not an ontological question. That which I can say about the subject on the basis of this question is not the same as what I can say on the basis of the ontological question. It is a different approach to the subject. "It is a semantics of proximity, of sociality" (p. 140).

The great challenge for Levinas, as well as for Habermas and for all intersubjectivity philosophies, is to escape from archeological thought, from the favoring of one particular type of relationship. This difficulty can be illustrated by the confrontation between Marcel (1978) and Buber (1970). The two authors meet in their parallel efforts to develop the originality of the intersubjective relation with respect to the subject-object relationship. The intersubjective relationship does not have a subject-object structure. In the subject-object relationship the subject is never for the object what the object is for the subject. The intersubjective relationship, by contrast, is complete reciprocity. There is an initial equality between the one who questions and the one who is questioned (Levinas, 1987, p. 36). Both authors express this in the same way. The meeting does not take place either in the one or in the other participant, but "in between them" (entre-les-deux). They are both in agreement that "sociality cannot be reduced to the experience of sociality" (p. 38).

After this, Buber and Marcel part ways. Subsequent development in their thinking illustrates how Marcel ultimately remains within the ontological framework and how Buber attempts to distance himself from it.

For Marcel (1978) the relation of an I and a Thou is an encounter which has the character of a co-presence. This encounter precedes word, language, and dialogue. Being in the presence of the other is, for Marcel, linked with subjectivity's state of being incarnate. The body is meditation, but not of an agent supposed to exist outside of it. In this sense, the being of the subject itself is always "exposure to the others" (exposition aux autres). The being of the subject is a co-esse. Intersubjectivity is a modality of being, of the Being. Dialogue becomes possible on this basis- on the basis of a preexisting structural nearness with respect to the subject. But in addition, according to Marcel, dialogue presup- 
poses a "mutual belonging to the same history" (Levinas, 1987, pp. 40-42) or "to the same destiny" (p. 44).

For Buber, by contrast, the encounter is unconditional, irreducible to a foundational unit and it coincides with speaking. The appearance of the other, for Buber, coincides with the encounter. The I or the Thou that a Thou or an I questions is "the basic fact" (le fait premier). The I-Thou is primary, not a we, but also not an I or a Thou. There is only the I of the I-Thou, or the Thou of the I-Thou (Levinas, 1987, p. 29). This is the meaning of Buber's basic terms. An I-Thou relationship is not a relationship between an I and a Thou that are supposed to exist apart from one another. I-Thou is relationship. "Sociality is dual." Levinas draws the conclusion from this: Speaking, for Buber, is not the announcement of an encounter. It is the happening of the encounter itself. The word is already dialogue (p. 61) and it constitutes an order which it is just as legitimate as that which is constituted through the knowledge relationship favored by tradition.

In speech, says Buber, one puts oneself in the universal, but why does one speak? Because one is questioned, says Buber. For Levinas, (1987) this answer is only valid when the questioning is not free of obligation. The one who addresses me is the one I am involved with, the one who draws me into an order which is another than that of the truth -an order in which, in contrast to Buber, the I is not the equal of the Thou, but "the first person in the accusative, and not in the nominative" (p. 65). The I that is questioned is the I that must justify itself--an I that is made responsible. It is a demand that is made of me. My uniqueness lies in the exclusivity of the question addressed to me, in the impossibility of passing on the question to a third party. The total reciprocity which for Buber typifies the I-Thou relationship lies in the fact that the Thou that is questioned by the I is assumed to be present as an I that says Thou. This total reciprocity can also be found in the demand, inherent in the communicative act, for equal opportunity for the interaction partners to make claims of validity. The initial equality is not retained by Levinas. Intersubjectivity is not total reciprocity, but "ethical inequality" (p. 65). The subject is "sub-jectum, responsible for everything" (Levinas, 1974, p. 147).

The $I$ is Ally

Subjectivity defined as autonomous self-determination realizes itself through the recuperation of the other than itself, that is, through an insight that leads to the control of nature outside of and within itself. Subjectivity becomes itself by withdrawing 
itself from alienation, by taking back into itself the engagement with the object (subjectivity's being outside itself with respect to the object) in a moment of reflection. Subjectivity which can only exist in engagement with reality-and so must necessarily lose itself-finds itself again in the moment of self-consciousness. Losing itself to the object is "an adventure that is no adventure," writes Levinas (1974), because "it is only a return to oneself" (p. 126).

Whenever subjectivity in the form of self-consciousness is permitted to fade away, to the advantage of a subjectivity which is communicative in its basic structure, then what remains of education? Indeed, the question which is being asked by many pedagogues with great insistence is: If we give up the idea of autonomy, then what meaning can education still have?

We need to clearly realize that the term education in this question implicitly receives a content which is inherently linked with the presuppositions of modernity. Are we giving up the possibility of education and responsibility if we give up the thought that I am the creator of my existence and of society? If we give up the idea that education is the realization of an I that comes into being by taking up the other than I-with which it is intertwined through the materiality of existence-into the rationality established by the I, then are we giving up the possibility of education itself? If we give up the thought that the I is responsible to the degree that it can take place itself under a self-chosen norm, then are we giving up the possibility of responsibility?

If we no longer share the presuppositions of modernity, then subjectivity means something else. For Habermas the subject has always been in communication. The subject is not the initiator of a social order, but finds itself in an order which Levinas says is ethical. The subject in the ethical order is the one who is called to responsibility. The $I$ is responsibility for that of which it is not the origin. The I, says Habermas, is ally, but in an alliance which is not the result of an agreement.

When education does not lead to autonomy, then where does it lead? Why are we asking this question? Because education is, in any case, linked to development. Education rides on the back of the phenomenon of development. Through the analyses of the philosophy of development, the suppositions inherent in the concept of development are sufficiently well known. Development implies progress. If education implies a development, then whenever we speak of education it is always a matter of transition from situation A to situation B. Situation A is traditionally 
viewed as the impossibility of having control over oneself; situation B coincides with autonomy. Education is the reversal of human existence. When subjectivity is defined as responsibility, then what is situation $A$ and situation $B$ ? Is there then actually no distinction between the two situations, unless on the level of the possibilities - the means_of taking on the responsibility under which I am placed? Taking the fact of development into consideration is only meaningful when we speak of being able and not being able. Being able and not being able has to do only with the concrete form which our responsibility assumes, which is an exponent of the communicative praxis to which we belong and which helps to determine our identity. Then what is education? Education is the inclusion of the child in the communicative praxis. Education is concerned with the cohabitation of older and younger generations. It is a living together in which, in a particularly forceful way, the question of meaning plays a part. Each new generation asks again the question whether it is right to be what we are. Each new generation finds itself as a partner in a society; it finds itself through the fact that it must act, that outside the interaction it cannot exist, and if finds itself in an identity which is also carried by the previous generation. The question as to whether it is right to be what we are is a question of justification which, however, always already implies the responsibility for what we are-for the older and for the younger generation. The uniqueness of the individual does not lie in the distinction, but in the exclusivity of the question addressed to me. $I$ am what is asked in this question-in an unavoidable way asked in this question. I is responsibility because the answer cannot be avoided. I cannot not answer because I cannot withdraw from interaction, and being in interaction means accepting and making claims.

To suppose that education is linked with the intention of an educator, who hereby takes on responsibility for the younger generation, is to leave open the possibility that this educator also may not be capable of doing this. This possibility does not actually exist. The older generation-the communicative praxis into which the younger generation is born-cannot renounce responsibility for this. It cannot choose whether or not it will enter into interaction with the younger generation. In all domains of communicative praxis, the older and younger generations are engaged as partners through the fact of existence.

The question which, understandably enough, on the basis of an existing educational practice comes up again and again is: Can educators then be trained? Is education an expertise that can be acquired? If it seems imaginable and meaningful in the dif- 
ferent domains of the communicative praxis to rationalize the societal legitimation, that is, to recomplete the communicative processes which play a role in it, then it is probably still also meaningful, in an explicit, if not privileged, manner, to involve the younger generation in this process. Professional educators are those who in the domain, or in a particular domain, of the communicative praxis have been involved in a more insistent way than others with the rationality proper to this domain, and thus they are able to involve others in it.

The intention of the argumentation which I have developed throughout this article is not to decide the debate which occasioned the article. It is rather an attempt, from the point of view of a pedagogical tradition, to take up the challenge of post-modernism. In my view, this implies that we cannot remain at the level of the surface contrasts, but that we must go back beyond the source of the pedagogical project to the intuition which was foundational for this project, because it is this intuition which is being called into question in the current discussion.

\section{References}

Apel, K.O. (1971). Scientistik, Hermeneutik, Ideologiekritik.

Entwurf einer Wissenschaftslehre in erkenntnisanthropologischer Licht. In Hermeneutik und Ideologiekritik (pp. 7-45). Mit Beitragen von Apel, Bormann, Bubner, Gadamer, Giegel, Habermas. Frankfurt a. Main: Suhrkamp.

Buber, M. (1970). I and thou. New York: Charles Scribner's Sons. Fink, E. (1970). Metaphysik der Erziehung im Weltverständnis von Plato und Aristoteles. Frankfurt a. M.: Vittorio Klostermann.

Habermas, J. (1981). Theorie des kommunikativen Handelns (2 vol.). Frankfurt a. Main: Suhrkamp.

Habermas, J. (1983a). Die Verschlingung von Mythos und Aufklärung. In K. Borer (Ed.), Mythos und Moderne (pp. 405-437). Frankfurt a. M.: Suhrkamp.

Habermas, J. (1983b). Simmel als Zeitdiagnostiker. Nachwort. In G. Simmel, Philosophische Kultur. Über das Abenteuer, die Geschlechter und die Krise der Moderne. Gesammelte Essais (pp. 243-253). Berlin: Verlag Klaus Wagengach.

Habermas, J. (1985). Der philosophische Diskurs der Moderne. Zwölf Vorlesungen. Frankfurt a. M.: Suhrkamp.

Hazard, P. (1961). La crise de la conscience européenne. 1680-1715. Paris: Fayard.

Horkheimer, M., \& Adorno, T.W. (1972). Dialectic of enlightenment (J. Cumming, Trans.). New York: Herder and Herder.

Levinas, E. (1951). L'ontologie est-elle fondamentale? Revue de Métaphysique et de Morale, 56, pp. 88-98.

Levinas, E. (1974). Autrement qu'être ou audelà de l'essence. The Hague: M. Nijhoff. 
Levinas, E. (1987). Hors sujet. Paris: Fata morgana.

Marcel, E. (1978). Homo viator, Introduction to a metaphysics of hope. Gloucester, MA: Peter Smith.

Masschelein, J. (1990). Pödagogisches und kommunikatives Handeln. Weinheim: Deutscher Studien Verlag.

Mollenhauer, K. (1986). Über Bildung, Kunst und Interaktion.

Weinheim, München: Juventa Verlag. 